Review Article

\title{
Simplified Modeling and Simulation of Electricity Production from a Dish/Stirling System
}

\author{
Mahamat Hassane Babikir (D, ${ }^{1}$ Venant Sorel Chara-Dackou, ${ }^{1}$ Donatien Njomo, ${ }^{1}$ \\ Mahamat Barka, ${ }^{2}$ Mahamoud Youssouf Khayal, ${ }^{2}$ Daniel Roméo Kamta Legue, ${ }^{1}$ \\ and Jean Paul Gram-Shou $\mathbb{D D}^{1}$ \\ ${ }^{1}$ Environmental Energy Technologies Laboratory (EETL), Department of Physics, University of Yaounde I, Cameroon \\ ${ }^{2}$ University of N'Djamena, Chad \\ Correspondence should be addressed to Mahamat Hassane Babikir; hassanemahamat6@gmail.com
}

Received 11 November 2019; Revised 9 February 2020; Accepted 25 February 2020; Published 31 March 2020

Guest Editor: Marco Rivera

Copyright (c) 2020 Mahamat Hassane Babikir et al. This is an open access article distributed under the Creative Commons Attribution License, which permits unrestricted use, distribution, and reproduction in any medium, provided the original work is properly cited.

\begin{abstract}
This work is part of the dynamic of proposing a solution to the problem of access to electricity in Chad, which has a rate of access to electricity of 3\%. N'Djamena has significant solar potential that can be harnessed to generate electricity. In this paper, we present a theoretical study of the performances of the Dish/Stirling system with the purpose of producing electricity, based on a mathematical model taking into account each of the subparts of the system (concentrator, solar cavity receiver, and Stirling engine). Hydrogen is preferred to helium as the working fluid for operating the Stirling engine at high temperatures. This coupled model made it possible to estimate the monthly average of the electric power produced by this modular system and also its overall solar electricity yield.
\end{abstract}

\section{Introduction}

Alarming reports of the unprecedented effects of fossil fuel use on the climate have been at the center of research into new technologies. The sun is one of the abundant sources of energy. Thermodynamic solar is one of the solar technologies that operate solar radiation to generate electricity. Its techniques are aimed at converting the sun's radiation into heat to heat a fluid at high temperature allowing driving a turbine or a motor to produce electricity and also heat for industrial processes. The Dish/Stirling system among the four (4) concentrated solar power systems of its modular nature is suitable for small-scale electricity production [1]. The use of this system is not limited to the production of electricity but in several areas. In their work, Petrescu et al. used the Dish/Stirling system to produce hydrogen compared to its performance with that of photovoltaic cells. The two systems are coupled to an electrolyser [2]. Nepveu et al. made an evaluation and a study of the optical and thermal losses of the Dish/Stirling system of $10 \mathrm{~kW}_{\text {elec }}$ in the laboratory of
PROMES, starting from a modeling of the solar energyelectricity conversion of this one, for electricity production [3]. Ahmadi et al. [4] made a thermodynamic analysis and used the algorithm of NSGAII to optimize the objective function associated with the power output, thermal for a motor with solar system in order to study the factors of optimal design, and the optimal thermoeconomic performances. Other work has been carried out on the use of the Stirling engine and its thermodynamic cycle. To improve the cooling system of a car engine, Bani-Hani et al. [5] carried out an experimental study to integrate a Stirling cycle unit on the car radiator, acting as a pressure relief valve for the radiator. Knowledge of the meteorological data of the site where the technology is implemented is essential for the proper functioning of the Dish/Stirling system [6]. There are different methods of predicting or estimating the daily global radiation from one region to another $[7,8]$.

This work deals with the production of electricity from solar energy using the Dish/Stirling modular system. It is a question of transforming the solar energy obtained from 
solar radiation into heat, using a solar parabolic dish concentrator which is then transmitted to the working fluid at high temperature thus producing mechanical energy via a Stirling engine and finally converted in electricity by means of an alternator.

The purpose of this present work is to theoretically estimate the temperature of the external surface of the solar absorber and that of the working fluid circulating in it, which constitutes the hottest part of the Stirling engine (engine inlet). Two working fluids are used in order to compare their maximum temperatures reached during the day and choose the one with good energy transport properties to finally produce electricity. Some models define a critical value where the temperature must not exceed relative to the thermophysical characteristics of the material of the receiver used [9]. This is not the case in this work.

\section{Site Location}

The region of N'Djamena is located in the Sahelian climate with a total surface area of $395 \mathrm{~km}^{2}$ the average value of the normal direct component per hour available; on any scale, it varies from 5 to $6 \mathrm{kWh} / \mathrm{m}^{2}$ for the favorable month and 2.5 to $3 \mathrm{kWh} / \mathrm{m}^{2}$ for the unfavorable month according to a study done on the estimation analysis of the direct solar radiation component by $[6,7]$. Table 1 presents the geographic coordinates and type of climate of the study site.

\subsection{System Description. The system studied is a Dish/Stirling} module of $10 \mathrm{~kW}_{\text {elec }}$. This system is composed of three main elements, namely, the solar parabolic dish concentrator, the solar receiver, and then the Stirling engine. The concentrator consists of an assembly of mirrors in a parabolic shape with good reflectivity coefficient. At the focus of the concentrator at a focal length $F$, the solar receiver is placed. The latter has a receiving cavity which serves to reduce losses by reflection (trapping solar radiation), losses by convection, and losses by radiation from the hot surface of the solar absorber and to attenuate the nonuniformity of the solar flux on the absorber (redistribute the flux by internal reflections). The aperture surface of the receiving cavity is in the form of a circle and distant from the solar absorber which is housed at the bottom thereof. The distribution of the energy flow over the surface of the solar absorber is nonuniform, generating temperature gradients. In this work, this temperature is assumed to be uniform over this entire surface. The solar receiver is the critical part of the system where several physical phenomena prevail, in particular: it is the site of heat losses. The transport properties of air, helium, and hydrogen were evaluated using the correlations proposed by Refs. [10, 11].

2.2. Methodology. The energy model of the solar electricity conversion of the Dish/Stirling system extends from the solar parabolic dish concentrator to the Stirling engine via the solar receiver. This model can be divided into three parts relative to the three main elements mentioned above the system.
TABle 1: The geographic data of the site.

\begin{tabular}{lccccc}
\hline $\begin{array}{l}\text { Position } \\
\text { studied }\end{array}$ & $\begin{array}{c}\text { Latitude } \\
\left({ }^{\circ}\right)\end{array}$ & $\begin{array}{c}\text { Longitude } \\
\left({ }^{\circ}\right)\end{array}$ & $\begin{array}{c}\text { Altitude } \\
(\mathrm{m})\end{array}$ & Climate & Albedo \\
\hline N'Djamena & 12.11 & 15.04 & 295 & Sahelian & 0.2 \\
\hline
\end{tabular}

Hydrogen and helium are used as the working fluid and are considered to be ideal gases.

2.2.1. The Solar Parabolic Dish Concentrator. The reflective surface of the concentrator only reflects part of the solar energy collected due to its geometric imperfections which cause the solar to result to overflow outside the aperture of the receiving cavity. We assumed these errors to be constant and were fixed from the expression of the interception factor, which is also taken as a constant in this work.

2.2.2. Solar Receiver with the Solar Absorber. Only part of the concentrated solar energy entering the receiving cavity is transmitted in the form of sensitive heat at high temperature to the working fluid of the Stirling engine, circulating in the absorber tubes, while the other part is lost in the ambient air by reflection, thermal radiation, and convection. In order to calculate the temperature of the absorber surface, the distribution of the energy flow arriving on the surface of the solar absorber is assumed to be uniform and so is the temperature.

2.2.3. Stirling Engine. The energy transmitted to the working fluid at the inlet of the Stirling engine is in reality completely converted into mechanical energy due to the various losses due to imperfect regeneration and the tortuous flow of the working fluid. In order to couple the system to the Stirling engine and simulate its performance, the so-called isothermal Schmidt model is used. It is a simplified model presenting limits compared to the other models existing in the literature, being more efficient than this one [12-14]. This work is not intended to do an indepth modeling of the engine. An electric generator with high efficiency is coupled to the motor to convert the mechanical power supplied by it into electricity.

The steps of this conversion are shown in Figure 1. Design parameters of Dish/Stirling and operations conditions used for the case study are given in Table 2 and the operation flowchart in Figure 2.

2.3. Optical Geometric Model. The solar parabolic dish concentrator collects and reflects the direct normal irradiation (DNI) on the receiving cavity aperture and then concentrated on the solar absorber located at the bottom of it. The system is mounted on a metal structure placed on the ground. Many geometrical parameters (focal length, inclination of the receiver, the rim angle of the solar parabolic dish concentrator, etc.) of the system influence its operation, especially in terms of the exchanges of energy flow between the solar parabolic dish concentrator and the receiver $[15,16]$. 


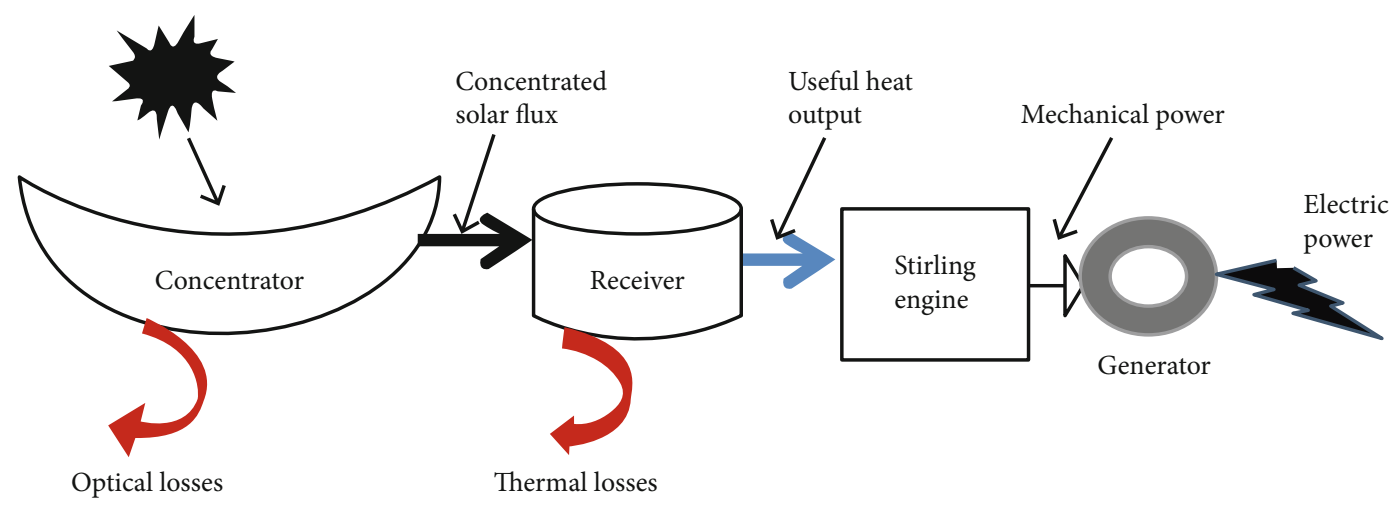

Figure 1: Diagram of the solar electricity conversion chain of the Dish/Stirling system.

TABle 2: Comparison between the model and the experimental measurements of the different yields of the subcomponents of the Dish/Stirling system.

\begin{tabular}{lccr}
\hline Data & $\begin{array}{c}\text { Mathematical model } \\
\text { used in this paper (\%) }\end{array}$ & $\begin{array}{c}\text { Experimental } \\
\text { measures [9] (\%) }\end{array}$ & $\begin{array}{r}\text { Errors between model and } \\
\text { experimental measures (\%) }\end{array}$ \\
\hline Collector efficiency & 75 & 78.6 & 4.5 \\
Receiving cavity efficiency & 88.4 & 82.6 & 7 \\
Thermooptical efficiency & 69 & 64.9 & 6.3 \\
Solar electricity efficiency & 21 & 22.5 & 6.7 \\
\hline
\end{tabular}

The diameter $D_{\text {con }}$ and the focal length of the collector $F$ are two important parameters of the structure and are described by Figure 3 . They are linked by the relation $[17,18]$

$$
\begin{aligned}
\frac{F}{D_{\text {con }}} & =\frac{1}{4 \cdot \tan (\psi / 2)}, \\
R_{\mathrm{P}} & =\frac{2 \cdot F}{1+\cos (\xi)},
\end{aligned}
$$

where $\varphi$ is the rim angle of the solar parabolic dish concentrator, $R_{\mathrm{P}}$ the parabolic radius (distance between the concentrator curve and the focal point), and $\xi$ is the angle that the parabolic radius makes with the distance (OM).

The solar parabolic dish concentrator plays a very important role in the solar electricity energy conversion chain. It presents several imperfections due to the geometrical defects and the shape of the sun causing the focal spot to overflow outside the aperture cavity: this represents the fraction of solar energy concentrated on the cavity aperture which did not enter into this one. Thus, these imperfections are evaluated from equation (2) [17]:

$$
\sigma_{\mathrm{T}}=4 \sigma_{\text {tilt }}^{2}+\sigma_{\text {spec }}^{2}+\sigma_{\mathrm{w}}^{2}+\sigma_{\text {sun }}^{2}
$$

The interception factor, which is the fraction of energy entering into the receiving cavity and is a function of the total error, is calculated by relation [16]:

$$
\phi_{\mathrm{fi}}=1-\exp \left(\frac{1}{2 \cdot C \cdot \sigma_{\mathrm{f}}^{2}}\right) .
$$

The lost energy (which is not entered) outside the cavity aperture area is deduced from the interception factor.

$C$ is the concentration factor defined as $C=A_{\text {con }} / A_{\text {ap }}$, where $A_{\text {con }}$ is the projected reflective surface of the solar parabolic dish concentrator and $A_{\text {ap }}$ is the aperture surface of the receiving cavity.

$\sigma_{\mathrm{f}}$ is the error of the distribution of heat flux in the focal plane which is given by [17]

$$
\sigma_{\mathrm{f}}^{2}=\sigma_{\mathrm{T}} \frac{1+\cos ^{2}(\psi)}{3 \cdot \psi \cdot \cos (\psi) \cdot \sin (\psi)} .
$$

2.4. Thermal Model. The expression of the power received by the aperture surface of the receiving cavity is given by the relation [19]

$$
\dot{Q}_{\mathrm{rec}}=\dot{Q}_{\mathrm{s}} \cdot \eta_{\mathrm{op}} \cdot \phi_{\mathrm{fi}}, \quad \dot{Q}_{\mathrm{s}}=I \cdot A_{\mathrm{con}}
$$

where $\eta_{\text {op }}$ is the optical efficiency of the solar parabolic dish concentrator which is defined as the product of the coefficient of absorptivity, emissivity, and transmissivity of the concentrator, $I$ is the direct normal irradiation, and $\dot{Q}_{s}$ is the power received at the reflective surface of the solar parabolic dish concentrator.

Within the receiver, the temperature is high, which generates several thermal losses through the aperture surface of the receiving cavity and the materials (ceramic and Inconel) constituting it.

2.4.1. Losses by Conducto-Convection. These losses are functions of the thermophysical properties of the material 


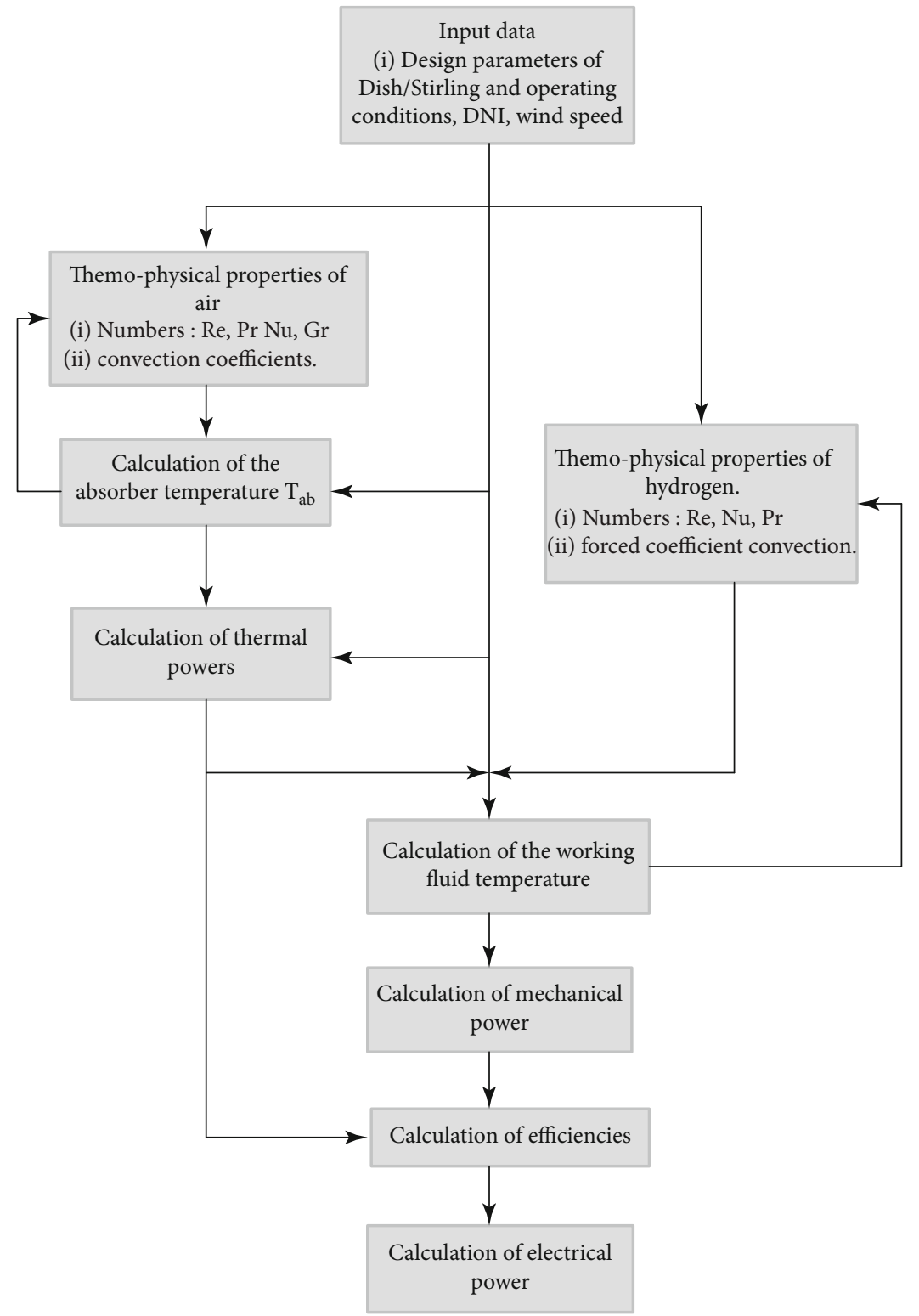

Figure 2: Operation flowchart.

constituting the walls. They represent the flow of heat conducted through the ceramic walls of the cavity (i.e., the side and back wall of the absorber) from the inside to the outside which is dissipated by natural convection into the ambient medium. In this work, unlike others, these losses are taken into account in the calculation because of the thermophysical properties of the material constituting the walls [9]. They are calculated by equation (6) as a function of the temperature difference [10]:

$$
\dot{Q}_{\mathrm{can}}=\frac{T_{\mathrm{ab}}-T_{\mathrm{amb}}}{\left(e_{\mathrm{cer}} / \lambda_{\mathrm{cer}} \cdot A_{\mathrm{in}}\right)+\left(1 / h_{\mathrm{ext}} \cdot A_{\mathrm{in}}\right)},
$$

where $\lambda_{\text {air }}$ and $\lambda_{\text {cer }}$ are the thermal conductivity of the ambient air and the ceramic, respectively; $e_{\text {cer }}$ and $A_{\text {in }}$ are the thickness of the ceramic wall and the inner surface of the ceramic wall, respectively; $T_{\mathrm{ab}}$ and $T_{\mathrm{amb}}$ are the temperature of the absorber and the ambient air, respectively; and $h_{\text {ext }}$ is the natural convection heat transfer coefficient outside the receiver. It is given by [10]

$$
h_{\text {ext }}=0.148 \cdot(\mathrm{Re})^{0.633} \cdot \frac{\lambda_{\text {air }}}{D_{\text {rec }}},
$$

where $D_{\text {rec }}$ is the diameter of the solar receiver and Re is the Reynolds number.

2.4.2. Convection Losses. Convective thermal losses are distinguished into two types of losses: natural convection and forced convection. Losses due to natural convection (inside the cavity) are due to the presence of air in the cavity and the level of temperature in it. They are proportional to the aperture surface of the cavity and then to the difference of 


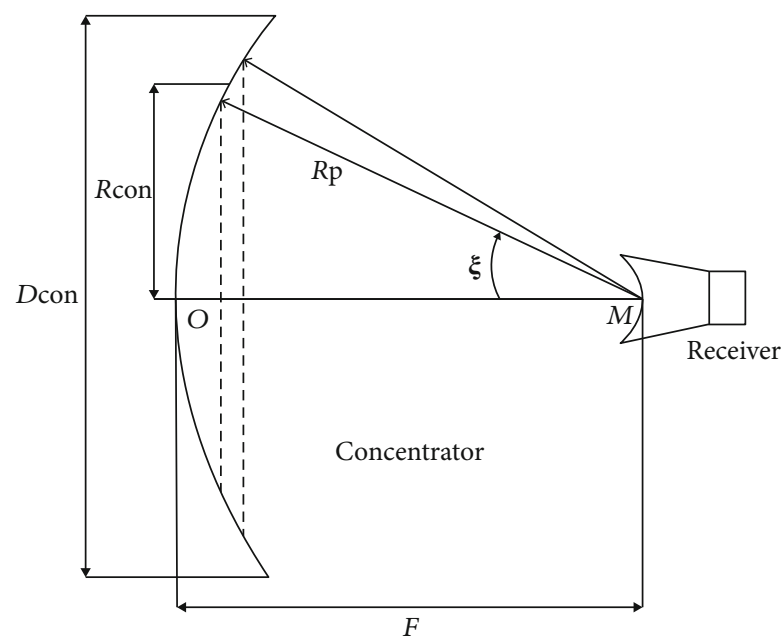

FIgURE 3: Geometry of the solar parabolic dish concentrator.

the temperatures between that of the absorber and the ambient air, while forced convection losses are due to the wind speed on the opening surface of the receiving cavity considering the inclination of the solar receiver. These losses are given by the relation [12]

$$
\dot{Q}_{\mathrm{conv}}=h_{\mathrm{total}} \cdot A_{\mathrm{ap}} \cdot\left(T_{\mathrm{ab}}-T_{\mathrm{amb}}\right)
$$

where $A_{\mathrm{ap}}$ is the aperture surface of the receiving cavity.

The total coefficient of convective transfer is given by [10]

$$
h_{\text {total }}=h_{\text {nat }}+h_{\text {forced }} \text {, }
$$

where

$$
\begin{aligned}
h_{\text {nat }} & =\frac{\mathrm{Nu} \lambda_{\text {air }}}{L}, \\
h_{\text {forced }} & =f(\theta) \cdot v^{1.401} .
\end{aligned}
$$

$L$ denotes the distance between the aperture of the receiving cavity and the solar absorber, $\theta$ characterizes the angle of inclination of the solar receiver relative to the horizontal, $v$ is the wind speed, and $f$ represents a function dependent on $\theta$ and is formulated by [10]

$$
\begin{aligned}
f(\theta)= & 0.1634+0.7498 \sin (\theta)-0.5026 \sin (2 \theta) \\
& +0.3278 \sin (3 \theta) .
\end{aligned}
$$

The correlations giving the Nusselt number and that of Grashof are concocted by equation (12) [10, 17, 18]:

$$
\begin{aligned}
& \mathrm{Nu}=0.088 \mathrm{Gr}^{1 / 3} \cdot\left(\frac{T_{\mathrm{ab}}}{T_{\mathrm{amb}}}\right)^{0.18} \cdot \cos (\theta)^{2.47} \cdot\left(\frac{D_{\mathrm{ap}}}{L}\right)^{S}, \\
& \mathrm{Gr}=\frac{g \beta\left(T_{\mathrm{ab}}-T_{\mathrm{amb}}\right) L^{3}}{v^{2}},
\end{aligned}
$$

where

$$
S=1.12-0.982 \cdot\left(\frac{D_{\mathrm{ap}}}{L}\right)
$$

where $g, \beta, v$, and $D_{\text {ap }}$ are the gravity, the coefficient of thermal expansion, the kinematic viscosity of the air, and the aperture diameter of the receiving cavity, respectively.

\subsubsection{Radiation Losses}

(1) Radiation. These are losses that are proportional to the emissivity of the absorber and to the aperture diameter of the receiving cavity. They strongly depend on the temperature difference between the reflective surface of the concentrator and that of the absorber. The relationship to calculate these losses is $[10,17]$

$$
\dot{Q}_{\mathrm{rad}}=\varepsilon_{\mathrm{ab}} \cdot \gamma \cdot A_{\mathrm{ap}} \cdot\left(T_{\mathrm{ab}}^{4}-T_{\mathrm{amb}}^{4}\right),
$$

where $\varepsilon_{\mathrm{ab}}$ and $\gamma$ denote the absorber emissivity and the Boltzmann factor, respectively.

(2) Reflection. These are losses by radiation coming from the reflection of the internal surfaces of the cavity. They depend on the absorptivity of the receiving cavity and are proportional to the power received by the receiving cavity. The relationship for calculating these losses is illustrated by equation (16) $[20,21]$ :

$$
\dot{Q}_{\text {ref }}=\left(1-a_{\text {eff }}\right) \cdot \dot{Q}_{\text {rec }}
$$

$$
a_{\mathrm{eff}}=\frac{a_{\mathrm{rec}}}{a_{\mathrm{rec}}+\left(1-a_{\mathrm{rec}}\right)\left(A_{\mathrm{ap}} / A_{\mathrm{rec}}\right)},
$$

where $a_{\text {eff }}, a_{\text {rec }}$, and $A_{\text {rec }}$ are the absorptivity coefficients of the cavity, receiver, and receiver surface, respectively.

2.4.4. Total Power Intercepted by the Solar Receiver. The available thermal power useful in the receiving cavity is estimated by the energy conservation equation:

$$
\dot{Q}_{\mathrm{u}}=\dot{Q}_{\mathrm{rec}}-\dot{Q}_{\mathrm{ref}}-\left(\dot{Q}_{\mathrm{cond}}+\dot{Q}_{\mathrm{conv}}+\dot{Q}_{\mathrm{ray}}\right) \text {. }
$$

This equation can be rewritten using the temperature formulation, in the form

$$
p \cdot C_{\mathrm{P}} \cdot V \frac{d T_{\mathrm{ab}}}{d t}=\dot{\mathrm{Q}}_{\mathrm{rec}}-\dot{\mathrm{Q}}_{\mathrm{ref}}-\left(\dot{\mathrm{Q}}_{\mathrm{cond}}+\dot{Q}_{\mathrm{conv}}+\dot{Q}_{\mathrm{ray}}\right)
$$

where $C_{\mathrm{P}}$ is the specific heat capacity, $\rho$ the density, and $V$ the volume of the ceramic wall and the air, respectively. Thus, equation (19) makes it possible to calculate the temperature of the surface of the solar absorber as a function of time.

The thermal power is transmitted to the working fluid circulating in the hot part of the engine in the form of 


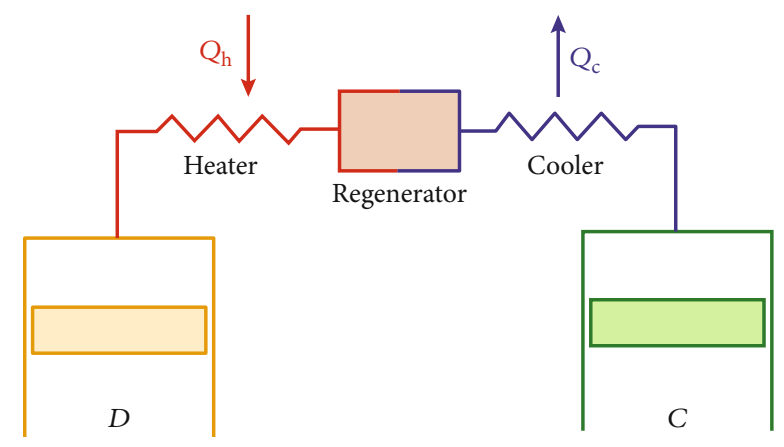

FIGURE 4: Diagram of the different compartments of the Stirling engine.

sensible heat. This makes it possible to calculate the temperature of the working fluid in the absorber tubes and is described by

$$
T_{\mathrm{f}}(t)=T_{\mathrm{ab}}(t)-\frac{Q_{\mathrm{u}}}{h_{\mathrm{cf}} \cdot A_{\mathrm{ab}}} .
$$

2.5. Model of Engine Stirling. The modeling of the Stirling engine is based on the Schmidt model called isothermal analysis, a mathematical model that allows to simulate the performance of a Stirling engine from its geometry. This analysis is described by Berchowitz and Urieli, published in their document Stirling Cycle Engine Analysis [21]. This analysis takes into account various simplifying assumptions [22]. Figure 4 shows the different sections of the Stirling engine considered in this analysis. The Stirling engine used is of the alpha Solo $\mathrm{V}-161$ type. The variations in its expansion and compression volumes are expressed from equations (21), valid for sinusoidal kinematics, and are a function of cycle time, phase shift, and speed of rotation $[3,9]$ :

$$
\begin{aligned}
& V_{\mathrm{C}}(t)=\frac{V_{\mathrm{C}}}{2}\left(\sin \left(\omega_{0} \cdot t-\zeta\right)+1\right)+V_{\mathrm{Cm}}, \\
& V_{\mathrm{D}}(t)=\frac{V_{\mathrm{D}}}{2}\left(\sin \left(\omega_{0} \cdot t\right)+1\right)+V_{\mathrm{Dm}} .
\end{aligned}
$$

The angular speed $\omega_{0}=\left(2 \pi \cdot N_{\mathrm{T}}\right) / 60$, function of rotation speed $N_{\mathrm{T}}=1500 \mathrm{rpm}$, and frequency is 25 hertz. The phase shift between the two pistons is $90^{\circ}$, that is to say, $2 \pi$ radians. The volumes of the other engine compartments are constant.

The total mass of the working fluid propagating into the engine is the sum of the masses of each compartment of the engine. It is constant and written in the form [23]

$$
M=m_{\mathrm{D}}+m_{\mathrm{h}}+m_{\mathrm{r}}+m_{\mathrm{c}}+m_{\mathrm{C}}
$$

Thus, the gas pressure in the entire engine can be written as a function of different temperatures, volume size of each compartment, and the noble gas constant. It is given by equation $(24)[24,25]$ :

$$
P=M \cdot R \cdot\left(\frac{V_{\mathrm{D}}}{T_{\mathrm{D}}}+\frac{V_{\mathrm{h}}}{T_{\mathrm{h}}}+\frac{V_{\mathrm{r}}}{T_{\mathrm{r}}}+\frac{V_{\mathrm{c}}}{T_{\mathrm{c}}}+\frac{V_{\mathrm{C}}}{T_{\mathrm{C}}}\right)^{-1},
$$

$$
\begin{aligned}
& Q_{\mathrm{h}}=W_{\mathrm{D}}=\oint P\left(\frac{d V_{\mathrm{D}}}{d \varphi}\right) d \varphi, \\
& Q_{\mathrm{c}}=W_{\mathrm{C}}=\oint P\left(\frac{d V_{\mathrm{C}}}{d \varphi}\right) d \varphi .
\end{aligned}
$$

The total work done by the system in a complete cycle is written as

$$
W=W_{\mathrm{D}}+W_{\mathrm{C}}
$$

The receptor efficiency is defined as the ratio between the supplied power to the working fluid in the Stirling engine and the received power by the receiving cavity. It takes into consideration losses due to conducto-convection, convection, reflection, and radiation from the receiving cavity opening and its walls.

$$
\eta_{\text {cav }}=\frac{\dot{Q}_{\mathrm{u}}}{\dot{Q}_{\mathrm{rec}}}
$$

The thermooptical efficiency is given as $[26,27]$

$$
\eta_{\text {thermoopt }}=\frac{\dot{Q}_{\mathrm{u}}}{I \cdot A_{\text {con }}} \text {. }
$$

That of the engine presents the thermal power supplied to the working fluid at the input of the engine, which converted into mechanical power at the output.

$$
\eta_{\text {engine }}=\frac{\dot{W}}{\dot{Q}_{u}} .
$$

Finally, the global system efficiency, which expresses the global performance of the solar electricity conversion chain of the Dish/Stirling system, is given by

$$
\eta_{\text {global }}=\eta_{\text {con }} \cdot \eta_{\text {cav }} \cdot \eta_{\text {engine }} \cdot \eta_{\mathrm{GE}}
$$

The supplied electric power by the electric generator coupled to the Stirling engine is calculated from

$$
\dot{Q}_{\mathrm{el}}=\eta_{\mathrm{global}} \cdot I \cdot A_{\mathrm{con}} \text {. }
$$

\section{Results}

Temperature is a very important parameter in the overall functioning of Dish/Stirling systems. It influences each step of their solar electricity conversion chain and finally their efficiency. Figure 5 illustrates the influence of the solar absorber temperature on the thermooptical system and the efficiency of the solar receiver. The temperature increase on the outer surface of the solar absorber related to the DNI generates thermal and optical losses inside the solar parabolic dish concentrator and the receiving cavity relative to the properties of the materials used by these. This is clearly described by Figure 5. Hydrogen and helium were used as working fluid to compare their maximum temperature 


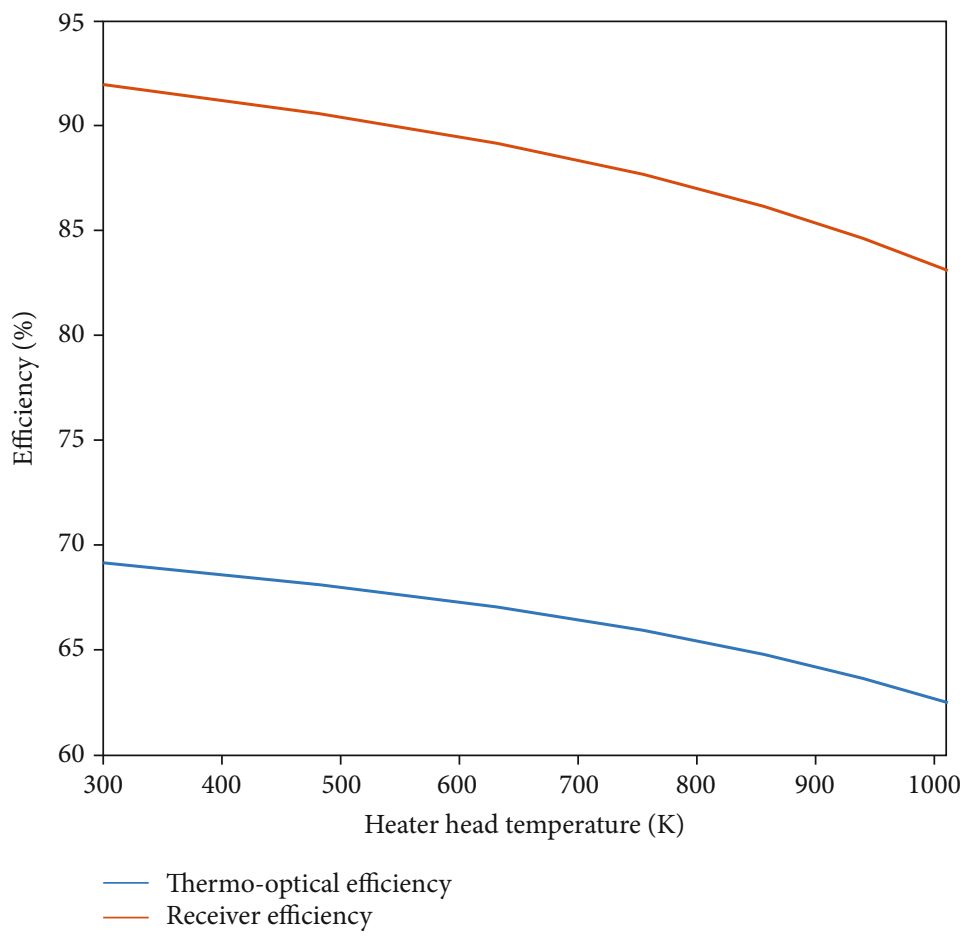

Figure 5: Evolution of the efficiency as a function of the absorber temperature.

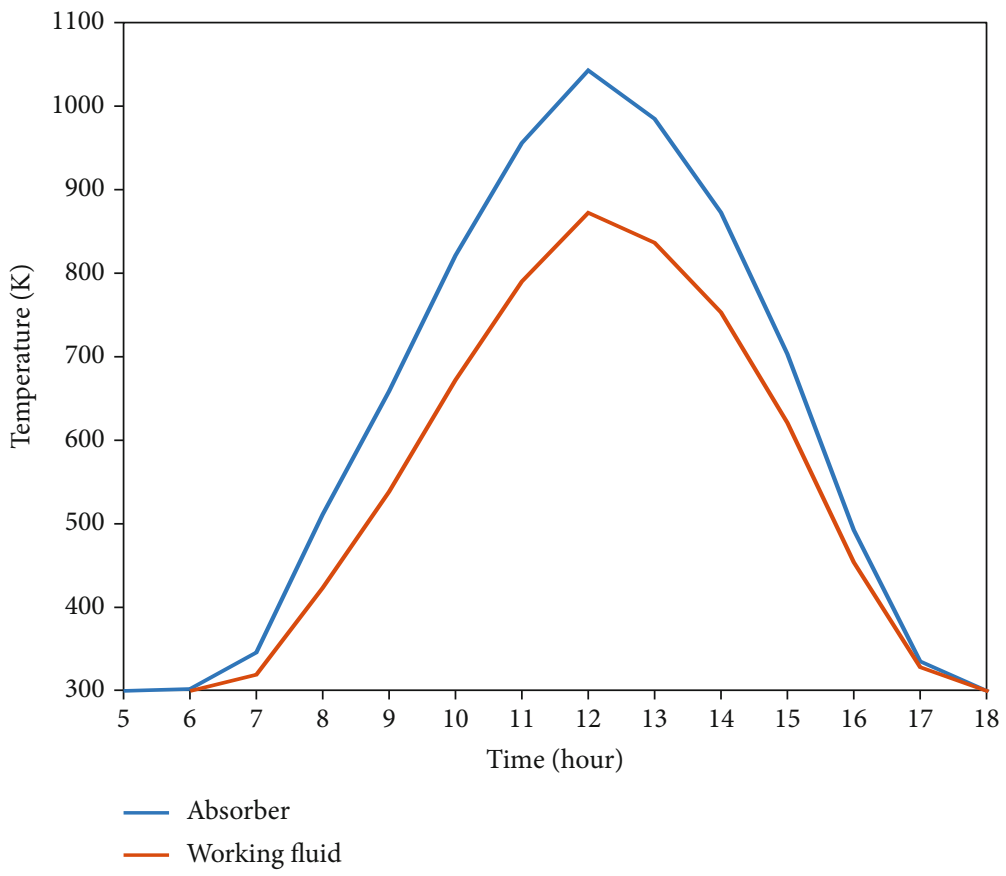

FiguRE 6: Evolution of the working fluid temperature in the heater for the most favorable month using hydrogen gas.

reached at the engine inlet, i.e., the temperature of the hot source. The evolution of the temperature of each of these working fluids in the heater as a function of time was simulated in order to see which of the two presents good energy transport properties. Figures 6-9 compare the variations of the temperature of the absorber $\left(T_{\mathrm{ab}}\right)$ and that of the working fluid $\left(T_{\mathrm{f}}\right)$ during the month of the year considered the most favorable and most unfavorable of the city of N'Djamena, first using hydrogen as a working fluid and then helium later. During the day for the most favorable month, both temperatures change according to the DNI. However, the difference between these temperatures (Figures 6 and 7) is due to thermal losses recorded within the receiving cavity, a function of the variation of normal direct irradiation (DNI). The 


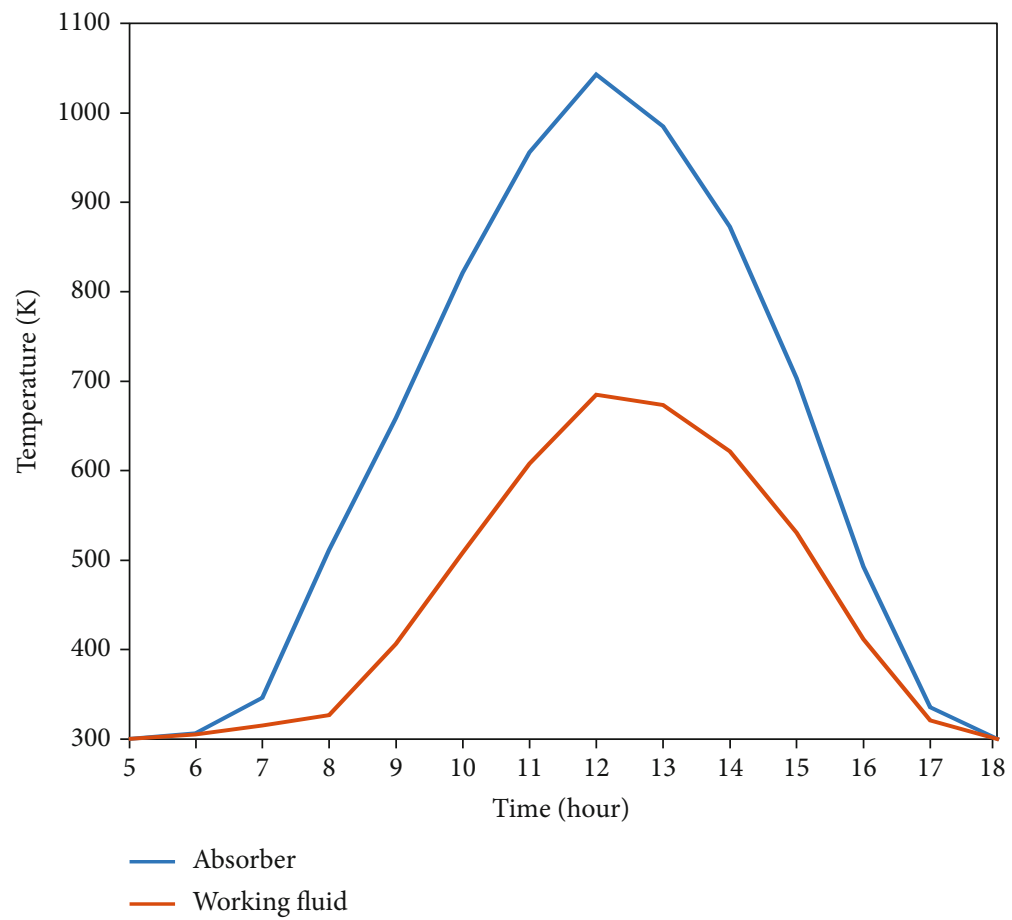

FIGURE 7: Evolution of the working fluid temperature in the heater for the most favorable month using helium.

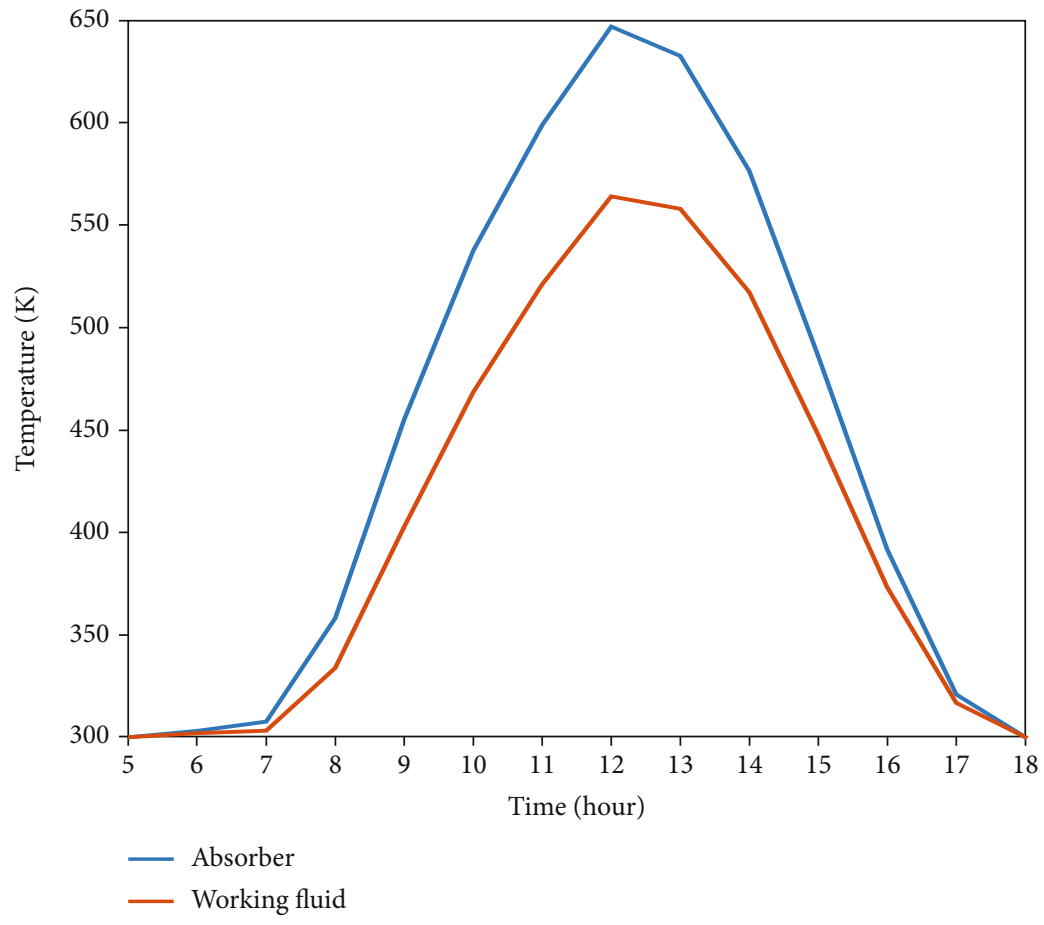

FIGURE 8: Evolution of the working fluid temperature in the heater for the most unfavorable month using hydrogen.

maximum values of the temperatures are reached when the direct normal irradiation reaches its maximum value. This comparison is made for the month of the year when DNI is most important (March). Hydrogen is used as a working fluid in Figure 5 and helium in Figure 6. The temperatures of the two fluids behave differently as a function of time and for the same variation of DNI. The maximum values attained by their temperature are shown in Figures 5 and 6 . These translate the behavior of the two fluids in the transport of energy. Thus, the evolutions highlight the good thermophysical properties (i.e., thermal conductivity, thermal capacity, dynamic viscosity, and density) of hydrogen with respect 


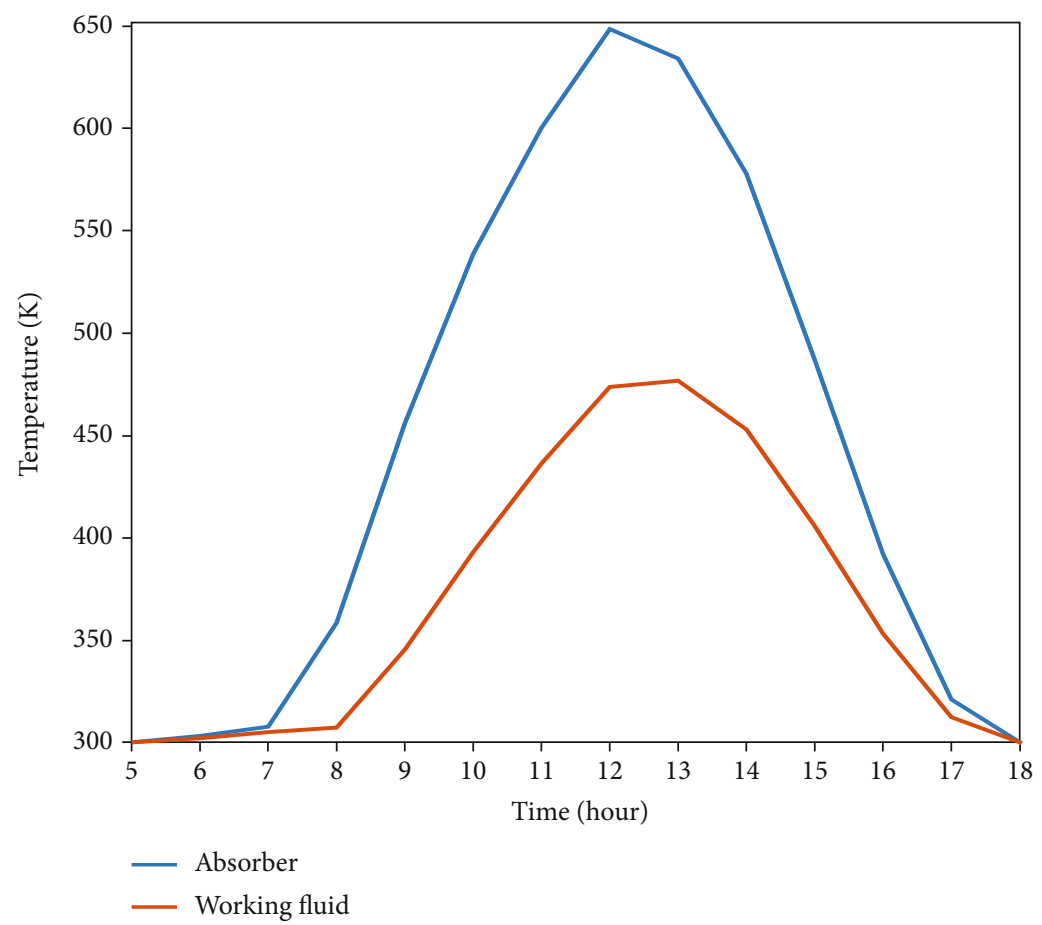

Figure 9: Evolution of the working fluid temperature in the heater for the unfavorable month using helium.

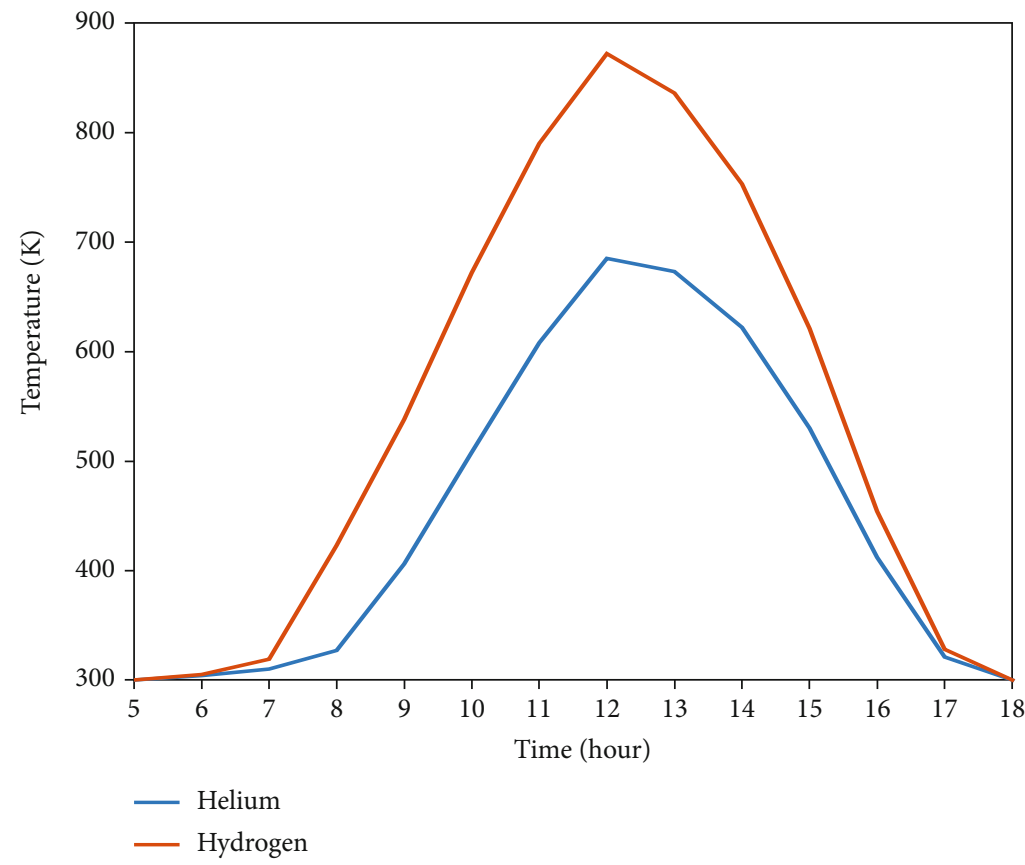

FIGURE 10: Temporal variation of the temperature of two working fluids used for the most favorable month.

to helium as a function of temperature. In general, the thermal efficiency and the fluid outlet temperature are used to evaluate the thermal performance of our system. The weather conditions are used for a typical March day with a wind speed of $2 \mathrm{~m} / \mathrm{s}$, and the fluid inlet temperature is assumed to be equal to the ambient temperature.
For the month (August) of the most unfavorable year, when DNI is not important, the two temperatures evolve similarly to the previous ones (Figures 7 and 8) during the day. Nevertheless, the differences observed between the two temperatures in Figures 7 and 8 are not the same in this case because DNI is low, which mitigates the thermal losses in the 


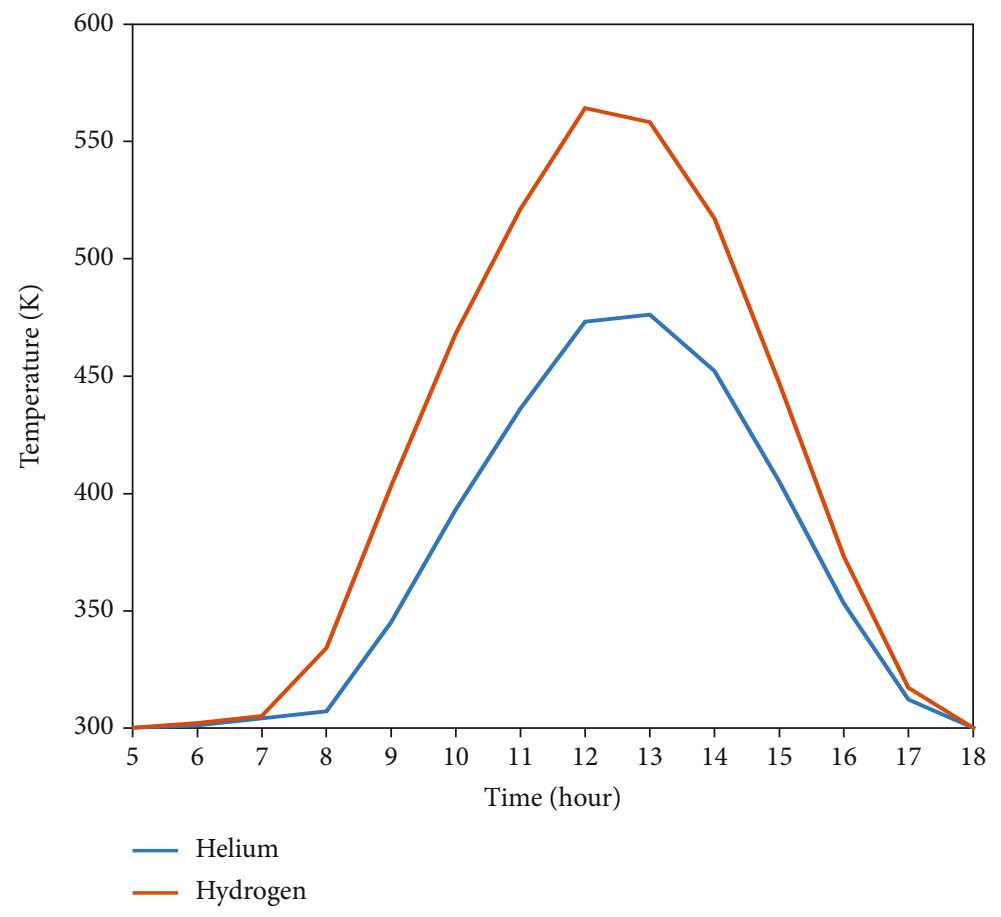

FIGURE 11: Temporal variation of the temperature of two working fluids used for the most unfavorable month.

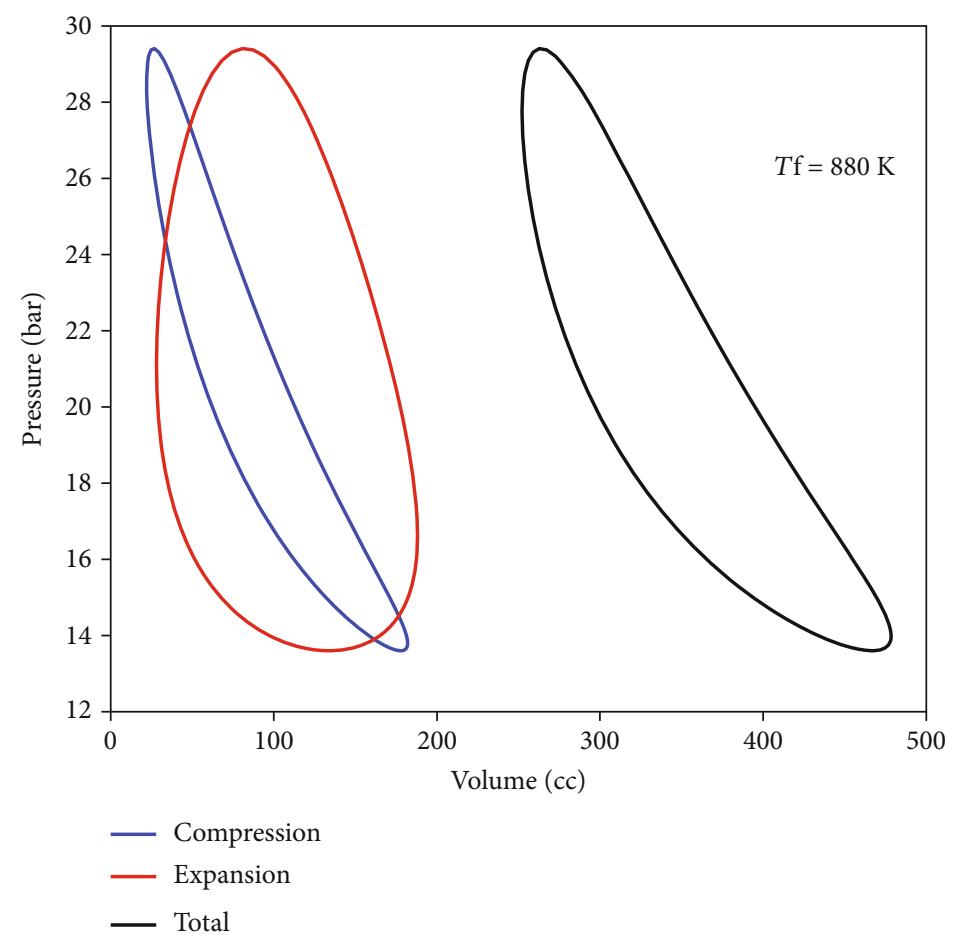

Figure 12: Theoretical PV diagram of the Stirling thermodynamic cycle.

solar receiver. The temperature difference between that of the solar absorber and that of the working fluid is proportional to the thermal losses. As before, hydrogen is considered (Figure 8) a working fluid at first and helium (Figure 9) in the second time. The same observations made previously in Figures 6 and 7 remain valid in these cases, except that the tem- peratures obtained are lower because the DNI here is also low. Figures 10 and 11 enable us to clearly appreciate the simultaneous temporal temperature fluctuations attained by the two used working fluid in the two different considered cases.

In the rest of the work, hydrogen is considered the only working fluid to simulate the performance of the Stirling 


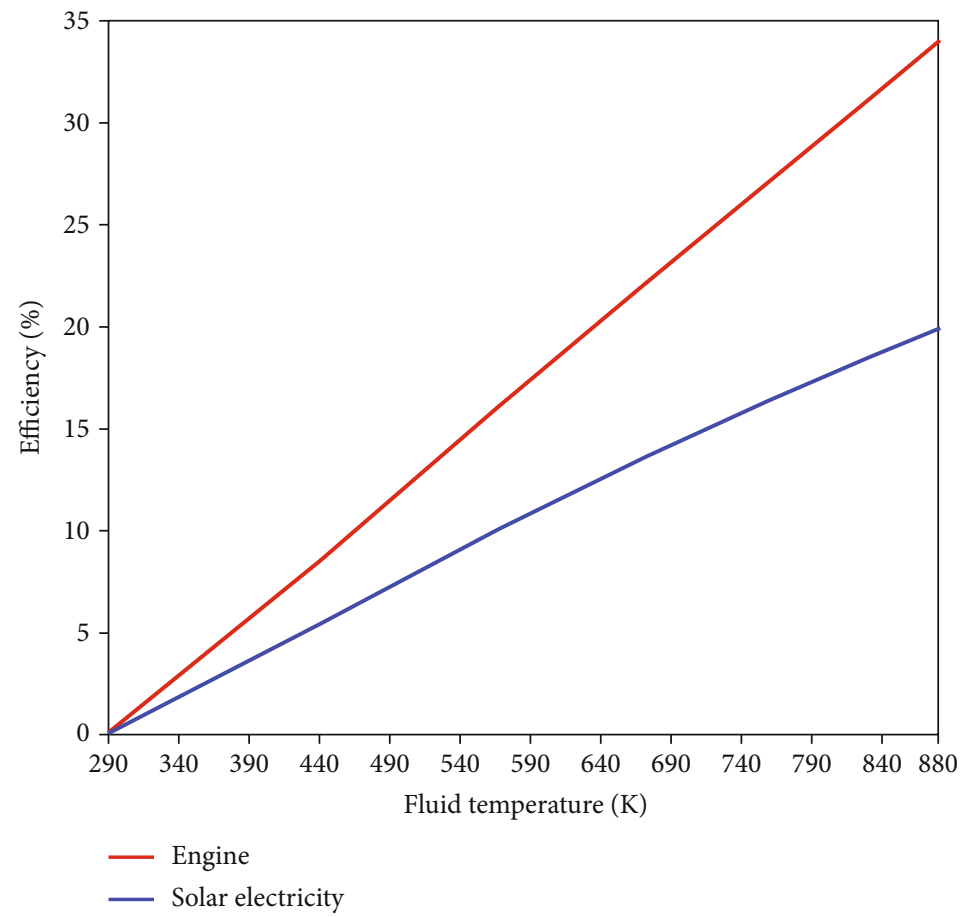

FIgURE 13: Evolution of the yields as a function of the temperature of the working fluid.

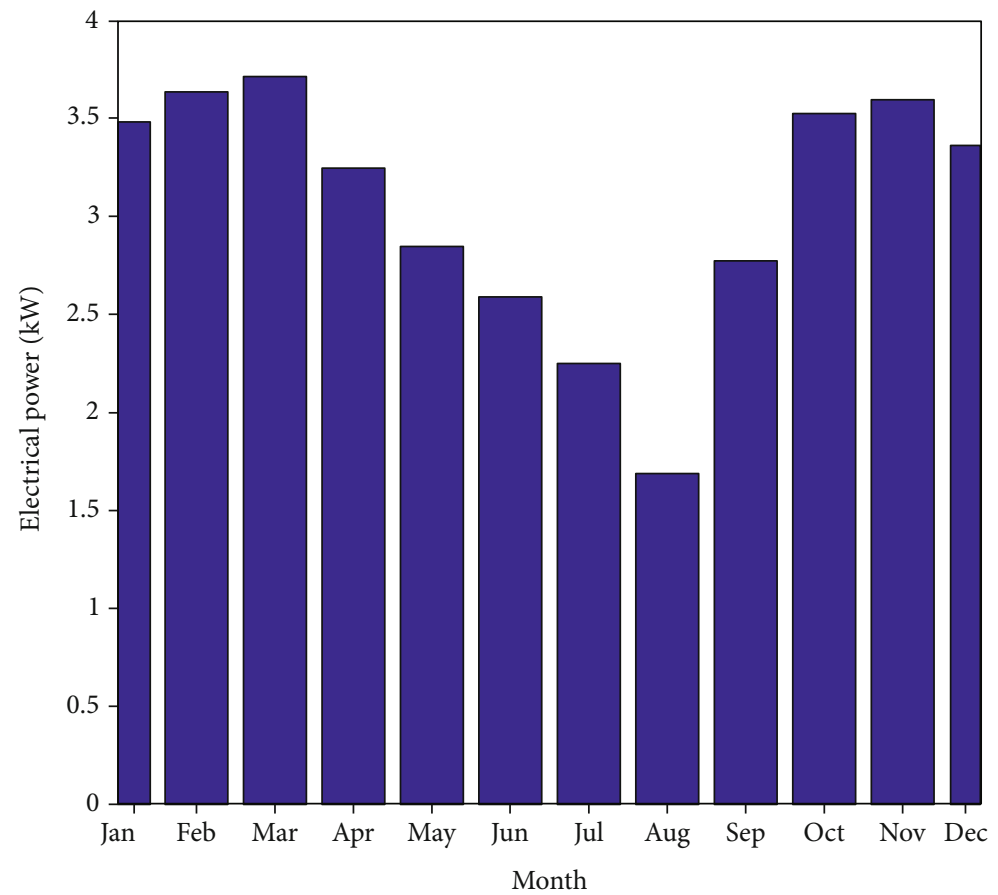

FIgURE 14: Variation of the monthly average of the daily electrical power.

engine because it has the good thermophysical properties at very high temperature degrees (i.e., low density, low viscosity, its high thermal mass capacity, and its high thermal conductivity too).

Figure 12 shows three curves describing the theoretical thermodynamic cycle carried out by the working fluid in the Stirling engine on the side of the expansion cylinder (curve in red) and of the compression cylinder (curve in blue) and in the whole of the Stirling engine (curve in black) representing the four (4) times of the Stirling cycle for a working fluid temperature at the inlet of the Stirling engine of $880 \mathrm{~K}$. This is the area representing the mechanical work provided by the pistons of the two cylinders during each cycle, for a full revolution of $2 \pi$. 
TABle 3: Design parameters of Dish/Stirling and operating conditions used for the case study [21].

\begin{tabular}{|c|c|}
\hline Type number of facets & Paraboloid 12 seg \\
\hline Focal length (m) & 4.52 \\
\hline Dish aperture diameter $(\mathrm{m})$ & 8.5 \\
\hline Area projected $\left(\mathrm{m}^{2}\right)$ & 56.7 \\
\hline Reflectivity (\%) & 94 \\
\hline Interception factor (\%) & 90 \\
\hline Rim angle $\left({ }^{\circ}\right)$ & 45 \\
\hline Stirling engine type & $\begin{array}{l}\text { Kinematic alpha } \\
\text { type SOLO } 161\end{array}$ \\
\hline Number of cylinders & 2 \\
\hline Maximum electrical power & $10 \mathrm{~kW}_{\mathrm{e}}$ \\
\hline Angular speed (rpm) & 1500 \\
\hline Working fluid & Hydrogen \\
\hline Cooling & Ambient air \\
\hline Cooler swept volume (cc) & 160 \\
\hline Cooler dead volume (cc) & 22 \\
\hline Heater swept volume (cc) & 160 \\
\hline Heater dead volume (cc) & 28,06 \\
\hline Absorber number of tubes & 78 \\
\hline Inner diameter of a tube (mm) & 1,6 \\
\hline Average length of a tube $\left(\mathrm{cm}^{2}\right)$ & 34,6 \\
\hline Absorber inner volume (cc) & 54,26 \\
\hline Area of absorber (cc) & 13,17 \\
\hline Regenerator diameter (mm) & 66 \\
\hline Regenerator heat transfer area $\left(\mathrm{cm}^{2}\right)$ & 25900 \\
\hline Length (mm) & 30,6 \\
\hline Ceramic thermal conductivity $\left(\mathrm{W} \cdot \mathrm{K}^{-1} \mathrm{~m}^{-1}\right)$ & 10 \\
\hline Thermal capacity of ceramic $\left(\mathrm{J} \cdot \mathrm{kg}^{-1} \cdot \mathrm{K}^{-1}\right)$ & 1000 \\
\hline Ceramic density $\left(\mathrm{kg} \cdot \mathrm{m}^{-3}\right)$ & 200 \\
\hline Ceramic thickness (m) & 0.20 \\
\hline Inconel thermal conductivity $\left(\mathrm{W} \cdot \mathrm{K}^{-1} \mathrm{~m}^{-1}\right)$ & 21 \\
\hline Thermal capacity of Inconel $\left(\mathrm{J} \cdot \mathrm{kg}^{-1} \cdot \mathrm{K}^{-1}\right)$ & 570 \\
\hline Inconel density $\left(\mathrm{kg} \cdot \mathrm{m}^{-3}\right)$ & 8440 \\
\hline Aperture diameter of cavity (m) & 0.19 \\
\hline Inclination angle $\left(^{\circ}\right)$ & 40 \\
\hline Phase shift angle $\left({ }^{\circ}\right)$ & 90 \\
\hline Depth of the cavity (m) & 0.12 \\
\hline
\end{tabular}

The performance of the system is evaluated on the basis of its performance. Several efficiencies have been defined in Section 2.5. Figure 13 illustrates the efficiency of the Stirling engine (curve in red) which describes the conversion of the thermal power supplied to the working fluid at the inlet of the engine into mechanical power at the outlet and the overall system performance (curve in blue). The latter expresses the overall performance of the solar electricity conversion chain of the Dish/Stirling system. It is the part of the solar energy collected and concentrated by the concentrator which is converted into electricity. Their changes are a function of the temperature of the working fluid driving the engine. The overall solar electricity yield of the system for a maxi- mum temperature of $880 \mathrm{~K}$ and a constant DNI of $906 \mathrm{~W} \cdot \mathrm{m}^{-2}$ is $21 \%$, which remains in the range defined by experimental measurements and other models reported in the literature [9].

The electrical power varies daily with respect to the performance of the system, which is influenced by the weather conditions in the study area. This has an impact on the average monthly production. Figure 14 shows these variations for each month of the year considered. Electric power increases during the first three (3) months of the year to $3.57 \mathrm{~kW}$ e (maximum) in March before decreasing to $1.57 \mathrm{~kW}_{\mathrm{e}}$ (minimum) in August. This result shows the importance of the concentrated solar system in the Sahel region of N'Djamena in Chad and also for the localities not connected to the electricity networks.

\section{Numerical Model Validation}

In order to validate the mathematical model used in the case of this study, we have considered the same input parameters used in the experimental study carried out by Refs. [3, 9]. Table 2 gives the differences between the different yields, defined in Section 2.5, estimated by the model and those obtained by the experimental measurements existing in the literature. These results are obtained for a constant DNI of $906 \mathrm{~W} \cdot \mathrm{m}^{-2}$, with hydrogen as working fluid and under the same operating conditions given in Table 3. The first difference between the model and the experimental measurements is at the level modeling the Stirling engine as you would expect, knowing the limits of the model used. The second difference is located at the receiver where simplifications have been made in particular on the distribution of the energy flow within it and the optical errors which have been fixed from the interception factor. The differences however remain within an acceptable range.

\section{Conclusion}

In this article, a study of the performance of the Dish/Stirling system for generating electricity was made, using a mathematical model coupling each of its subsystems. The temperatures reached at the inlet of the Stirling engine by the two working fluids used (hydrogen and helium) were estimated and compared. We can conclude that hydrogen is the good working fluid in the transport of energy at high temperature to drive the Stirling engine. It is then used in the rest of the work to estimate the electrical power produced by the system. Based on calculations, the performance of the subsystems was estimated from the mathematical model used. The results were compared with those obtained experimentally existing in the literature.

\section{Nomenclature}

$\begin{array}{ll}\%: & \text { Percentage } \\ \mathrm{K}: & \text { Kelvin } \\ \mathrm{W} / \mathrm{m}^{2}: & \text { Watt per square meter } \\ \mathrm{km}: & \text { Kilometer }\end{array}$




\begin{tabular}{|c|c|c|c|}
\hline ms: & Millisecond & $Q_{\text {cond }}:$ & Power lost through conducto-convection \\
\hline $\mathrm{kWh} / \mathrm{m}^{2} /$ day: & Kilowatt hours per square meter per day & $\dot{Q}_{\text {conv }}:$ & Power lost through convection \\
\hline$F:$ & Focal length & $\dot{Q}_{\mathrm{rad}}:$ & Power lost through radiation \\
\hline$R_{\mathrm{P}}:$ & Parabolic radius & $\dot{Q}_{\mathrm{u}}:$ & Useful power \\
\hline$R_{\text {con }}:$ & Concentrator radius & $L:$ & Depth of the cavity \\
\hline & $\begin{array}{l}\text { Angle between RP and distance (OM) } \\
\text { Rim angle }\end{array}$ & $\eta_{\text {cav }}:$ & Efficiency of the cavity \\
\hline$\theta$ & Inclination angle & $\eta_{\text {thermoopt }}:$ & Thermooptical efficiency \\
\hline$\zeta:$ & Phase shift angle & $\eta_{\text {engine }}:$ & Engine efficiency \\
\hline$\chi:$ & Degree angle & $\eta_{\text {global }}:$ & Overall system performance \\
\hline$\varphi:$ & Angle of crankshaft & $A_{\text {con }}:$ & Area of the concentrator \\
\hline$\lambda_{\text {cer }}:$ & Thermal conductivity of ceramic & $A_{\mathrm{ap}}:$ & Aperture area of the receiving cavity \\
\hline$\lambda_{\text {air }}:$ & Thermal conductivity of the air & $A_{\text {rec }}:$ & Area of receiver \\
\hline$\lambda_{\mathrm{T}}:$ & Total thermal conductivity & $A_{\text {in }}:$ & Inner area of the ceramic wall \\
\hline$\lambda_{\mathrm{ab}}$ & Thermal conductivity of the absorber & $A_{\mathrm{ab}}:$ & Area of absorber \\
\hline & (Inconel) & $T_{\mathrm{m}}:$ & Average temperature \\
\hline$\lambda_{\text {hyd }}:$ & Thermal conductivity of hydrogen & $T_{\mathrm{r}}:$ & Regenerator temperature \\
\hline$h_{\text {ext }}:$ & $\begin{array}{l}\text { Coefficient of natural convection transfer } \\
\text { outside receiver }\end{array}$ & $\begin{array}{l}T_{\mathrm{amb}}: \\
T_{\mathrm{ab}}:\end{array}$ & $\begin{array}{l}\text { Ambient temperature } \\
\text { Absorber temperature }\end{array}$ \\
\hline$h_{\text {total }}:$ & Total convection heat transfer coefficient & $T_{\mathrm{f}}:$ & Working fluid temperature \\
\hline$h_{\text {nat }}:$ & Natural convection heat transfer coefficient & $T_{\mathrm{h}}:$ & Heater temperature \\
\hline$h_{\text {forced }}:$ & Forced convection heat transfer coefficient & $W_{\mathrm{C}}:$ & Work on the compression side \\
\hline$h_{\mathrm{cf}}:$ & Forced convection heat transfer coefficient & $W_{\mathrm{D}}:$ & Relaxation work \\
\hline & (hydrogen) & $I:$ & Direct normal irradiation (DNI) \\
\hline$\alpha_{\text {eff }}:$ & Absorption coefficient of the receiving cavity & $V_{\mathrm{cm}}:$ & Cooler dead volume \\
\hline$\alpha_{\text {rec }}:$ & Receiver absorptivity coefficient & $V_{\mathrm{dm}}:$ & Heater dead volume \\
\hline$\beta:$ & Coefficient of thermal expansion & $V_{\mathrm{d}}:$ & Heater swept volume \\
\hline$\varepsilon_{\mathrm{ab}}$ & Emissivity coefficient of the absorber & $V_{\mathrm{c}}:$ & Cooler swept volume \\
\hline$C_{\mathrm{p}}:$ & Thermal capacity & $N_{\mathrm{T}}:$ & Rotation speed \\
\hline$R:$ & Constant of perfect gases & $t:$ & Time. \\
\hline
\end{tabular}

$D$ : $\quad$ Diameter of pipe

$D_{\text {con }}$ : Concentrator diameter

$D_{\text {rec }}$ : $\quad$ Receiver diameter

$D_{\mathrm{ap}}$ : $\quad$ Aperture diameter of the receiving cavity

$D_{\text {int }}$ : $\quad$ Inner diameter of the solar absorber tubes

$D_{\text {in }}$ : $\quad$ Diameter of a tube

$\sigma_{\mathrm{T}}: \quad$ Total error in the tilt concentrator

$\sigma_{\text {tilt }}: \quad$ Tilt error

$\sigma_{\mathrm{w}}: \quad$ Tracking system error

$\sigma_{\text {spec }}$ : $\quad$ Error due to specular reflectance of the concentrator

$\sigma_{\text {sun }}: \quad$ Error due to the shape of the sun

$e: \quad$ Thickness of the ceramic

$\phi_{\mathrm{fi}}: \quad$ Interception factor

C: $\quad$ Concentration factor

$v$ : Wind speed

$s: \quad$ Parameter of Equation

$\gamma: \quad$ Boltzmann factor

$f: \quad$ Frequency

$g: \quad$ Gravitational force

$\rho_{\mathrm{m}}: \quad$ Density

Re: $\quad$ Reynolds number

$\mathrm{Nu}$ Nusselt number

Gr: $\quad$ Grashof number

Pr: $\quad$ Prandtl number

$\dot{Q}_{s}: \quad \quad \quad$ Power received by the concentrator

$\dot{Q}_{\text {rec }}$ : $\quad$ Power received by the receiver

$\dot{Q}_{\text {ref }}$ : $\quad$ Power lost by reflection

\section{Conflicts of Interest}

The authors declare that they have no conflicts of interest.

\section{References}

[1] S. Quoilin, Concentrating solar power plants, University of LIEGE, Belgium, 2006.

[2] S. Petrescu, M. Costea, S. Petre, and O. Malancioiu, "Estimation and comparison of the performances of two hydrogen production processes using solar energy," in French Thermal Congress, SFT 2007, Ile des Embiez, 2007.

[3] F. Nepveu, A. Ferriere, F. D Baille, I. Verdier, and P. Lefevre, "Energy modeling of the Dish / Stirling EURODISH electricity production system," in French Thermal Congress, SFT 2007, vol. 1, Embiez Island, 2007.

[4] M. Hossein Ahmadi, S. Dehghani, A. H. Mohammadi, M. Feidt, and M. A. Barranco-Jimenez, "Optimal design of a solar driven heat engine based on thermal and thermo- economic criteria," Energy Conversion and Management, vol. 75, pp. 635-642, 2013.

[5] E. Bani-Hani, M. El HajAssad, M. Tawalbeh, B. Yousef, and A. Sedaghat, "Enhancing cooling system of a combustion engine by integrating with a stirling cycle," Energy Engineering, vol. 116, no. 3, pp. 41-53, 2019.

[6] M. Hassane Babikir, D. Njomo, M. Y. Khayal, H. D. Temene, and D. T. Joel, "Estimation of direct solar radiation of Chad," Engineering, Energy and Power, vol. 10, no. 5, pp. 212-225, 2018. 
[7] M. Hassane Babikir, D. Njomo, M. Barka et al., "Modeling the incident solar radiation of the city of N'Djamena (Chad) by the Capderou method," International Journal of Photoenergy, vol. 2020, Article ID 6292147, 10 pages, 2020.

[8] A. Khosravi, R. O. Nunes, M. E. H. Assad, and L. Machado, "Comparison of artificial intelligence methods in estimation of daily global solar radiation," Journal of Cleaner Production, vol. 194, pp. 342-358, 2018.

[9] F. Nepveu, Decentralized production of electricity and heat by Dish / Stirling system: application to the EURODISH system, [M.S. thesis], University of Perpignan, 2008.

[10] R. Beltran, N. Velazquez, A. C. Espericueta, D. Sauceda, and G. Perez, "Mathematical model for the study and design of a solar dish collector with cavity receiver for its application in Stirling engines," Journal of Mechanical Science and Technology, vol. 26, no. 10, pp. 3311-3321, 2012.

[11] H. Petersen, The properties of helium: density, specific heats, viscosity, and thermal conductivity at pressures from 1 to 100 bar and from room temperature to about $1800 \mathrm{~K}$, Risø National Laboratory, Roskilde, Denmark, 1970.

[12] M. Hossein Ahmadi, H. Sayyaadi, S. Dehghani, and H. Hosseinzade, "Designing a solar powered Stirling heat engine based on multiple criteria: maximized thermal efficiency and power," Energy Conversion and Management, vol. 75, pp. 282-291, 2013.

[13] M. H. Ahmadi, S. S. G. Aghaj, and A. Nazeri, "Prediction of power in solar Stirling heat engine by using neural network based on hybrid genetic algorithm and particle swarm optimization," Neural Computing and Applications, vol. 22, pp. 11411150, 2013.

[14] M. Hossein Ahmadi, M. Ali Ahmadi, A. Mellit, F. Pourfayaz, and M. Feidt, "Thermodynamic analysis and multi objective optimization of performance of solar dish Stirling engine by the centrality of entransy and entropy generation," Electrical Power and Energy Systems, vol. 78, pp. 88-95, 2016.

[15] A. Abdollahpour, M. H. Ahmadi, and A. H. Mohammadi, "Thermodynamic model to study a solar collector for its application to Stirling engines," Energy Conversion and Management, vol. 79, no. 2014, pp. 666-673, 2014.

[16] M. Bensafi, S. Zegnoun, and B. Draoui, Experimental study and modeling of a solar parabolic concentrator in the region of BecharENERGARID Laboratory, University of Bechar.

[17] L. Mingzhen and D. Jinzhong, Modeling and simulation of solar Dish/Stirling systems, School of Jet Propulsion Beijing University of Aeronautics and Astronautics Beijing, China, 2012.

[18] A. Z. Hafez, A. Soliman, K. A. el-Metwally, and I. M. Ismail, "Solar parabolic dish Stirling engine system design, simulation, and thermal analysis," Energy Conversion and Management, vol. 126, no. 2016, pp. 60-75, 2016.

[19] J. Ruelas, N. Velázquez, and R. Beltrán, “Opto-geometric performance of fixed-focus solar concentrators," Solar Energy, vol. 141, no. 2017, pp. 303-310, 2017.

[20] R. Beltrán-Chacon, D. Leal-Chavez, D. Sauceda, M. PellegriniCervantes, and M. Borunda, "Design and analysis of a dead volume control for a solar Stirling engine with induction generator," Energy, vol. 93, pp. 2593-2603, 2015.

[21] D. Berchowitz and I. Uriel, "Schmidt analysis for Stirling engines, document," in Stirling Cycle Engine Analysis, Adam Hilger Ltd, Bristol, 1st edition, 1984.
[22] K. Hicham, Comparative study and energy efficiency of different degrees of concentration of thermodynamic converters of solar energy, AbouBahr Belkaid-Tlemcen University, 2011.

[23] W. Jan and Prymon, "Mathematical modeling of the Stirling engine Marek," Procedia Engineering, vol. 157, pp. 349-356, 2016.

[24] N. Martaj and P. Rochelle, "1D modelling of an alpha type Stirling engine," International Journal for Simulation and Multidisciplinary Design Optimization, vol. 5, article A07, 2014.

[25] D. Ipci and H. Karabulut, "Thermodynamic and dynamic analysis of an alpha type Stirling engine and numerical treatment," Energy Conversion and Management, vol. 169, pp. 34-44, 2018.

[26] M. H. Ahmadi, A. H. Mohammadi, S. Dehghani, and M. A. Barranco-Jiménez, "Multi-objective thermodynamic-based optimization of output power of solar Dish-Stirling engine by implementing an evolutionary algorithm," Energy Conversion and Management, vol. 75, pp. 438-445, 2013.

[27] A. Khosravi, M. Malekan, and M. E. H. Assad, "Numerical analysis of magnetic field effects on the heat transfer enhancement in ferrofluids for a parabolic trough solar collector," Renewable Energy, vol. 134, pp. 54-63, 2019. 